\title{
Fullerene/MWCNT/Nafion Modified Glassy Carbon Electrode for the Electrochemical Determination of Caffeine
}

\author{
Kevin Yemele Tajeu, Liliane Medonbou Dongmo, Ignas Kenfack Tonle* \\ Electrochemistry and Chemistry of Materials, Department of Chemistry, University of Dschang, Dschang, Cameroon \\ Email: ${ }^{*}$ ignas.tonle@univ-dschang.org
}

How to cite this paper: Tajeu, K.Y., Dongmo, L.M. and Tonle, I.K. (2020) Fullerene/MWCNT/Nafion Modified Glassy Carbon Electrode for the Electrochemical Determination of Caffeine. American Journal of Analytical Chemistry, 11, 114-127. https://doi.org/10.4236/ajac.2020.112009

Received: October 9, 2019

Accepted: February 25, 2020

Published: February 28, 2020

Copyright $\odot 2020$ by author(s) and Scientific Research Publishing Inc. This work is licensed under the Creative Commons Attribution International License (CC BY 4.0).

http://creativecommons.org/licenses/by/4.0/

\begin{abstract}
Herein, a convenient method based on a fullerene/multiwalled carbon nanotube/Nafion modified glassy carbon electrode (fullerene/MWCNT/Naf/GCE) for the electrochemical determination of caffeine (CAF) is reported. Cyclic voltammetry (CV) and electrochemical impedance spectroscopy (EIS) were used to study ionic exchange properties and conductivity the proposed electrode using $\left[\mathrm{Fe}(\mathrm{CN})_{6}\right]^{3-/ 4-}$ redox couple. Caffeine gave an irreversible oxidation peak around $+1.33 \mathrm{~V}$ (vs. $\mathrm{Ag} / \mathrm{AgCl}$ reference electrode) in $\mathrm{HClO}_{4}(\mathrm{pH} 1)$. The linear dependence of the peak current with the square root of the scan rate showed that the electron transfer process is controlled by diffusion. After optimization of key analytical parameters involved in differential pulse voltammetry (DPV), the oxidation peak current varied linearly with CAF concentration in the range of 10 to $1000 \mu \mathrm{M}$. A detection limit of $7.289 \times 10^{-8} \mathrm{M}$ $(\mathrm{S} / \mathrm{N}=3)$ was found. Kinetic and chronocoulometric studies were also performed to characterize the diffusion of CAF. The developed electrode exhibited good stability and was easily regenerated. The influence of some potential interfering compounds such as dopamine, uric acid, glucose and sulfite ions on the anodic peak current of CAF was also examined. The proposed method was successfully employed in the determination of CAF in some commercial drugs.
\end{abstract}

\section{Keywords}

Caffeine, Fullerene/MWCNT, Nafion, Film Modified Electrode, Electroanalysis

\section{Introduction}

The analysis of drugs is of key importance in drug quality control. In this line, 
the development of sensitive, simple and rapid methods for the determination of active ingredients in drugs is a daily task for researchers working in analytical sciences. Food and pharmaceutical industries use caffeine (Scheme 1) in a wide range of products such as tea, coffee, soft drinks and medications [1] [2]. Most neuroprotective and metabolic benefits commonly associated with coffee and tea consumption have often been linked to caffeine content of these beverages [3]. Caffeine promotes gastric acid secretion and diuresis; and stimulates the central nervous [4] [5] [6] and the cardiovascular systems [7] [8]. It is however known that a high concentration of caffeine is toxic for the human body: it can cause nausea, trembling, nervousness, depression, hyperactivity and mutation effects [7] [9]. It constitutes a risk factor for cardiovascular diseases and asthma disease [4] [10]. The consumption of caffeine above $200 \mathrm{mg} /$ day may lead to death [11]. Therefore, several effective methods have been developed for the detection and quantification of caffeine in various samples. Amongst these methods, the most used are simple chromatographic methods [12] [13] [14], coupled in some cases with mass spectrometry [15] [16]. These techniques are usually expensive and time-consuming when compared to electrochemical methods [17]. However, the high positive oxidation potential of caffeine limits the use of common electrodes such as glassy carbon electrode [18] and carbon paste electrode [19]. Nafion (Naf) is widely used as chemical modifier due to its capacity to decrease the oxidation potential of some organic compounds. It is a perfluorinated sulfonated cation exchanger polymer widely used in electrochemistry to modify electrodes because it possesses many excellent properties such as chemical inertness, thermal stability, capacity, mechanical strength, huge cation exchange and antifouling properties [20]. Several nafion-based composite electrodes were used for the quantification of caffeine, that include nafion/modified boron-doped diamond [21], nafion/carbon nanotube [22], nafion/graphene modified electrode [23], nafion modified carbon electrode [24], nafion/graphite nanoplatelets [25], nafion/attapulgite [26] and nafion-ruthenium oxide pyrochlore modified glassy carbon electrode [27].

Besides, fullerene/multiwalled carbon nanotubes (MWCNT) are important electrode modifiers due to their favorable role in the promotion of electron

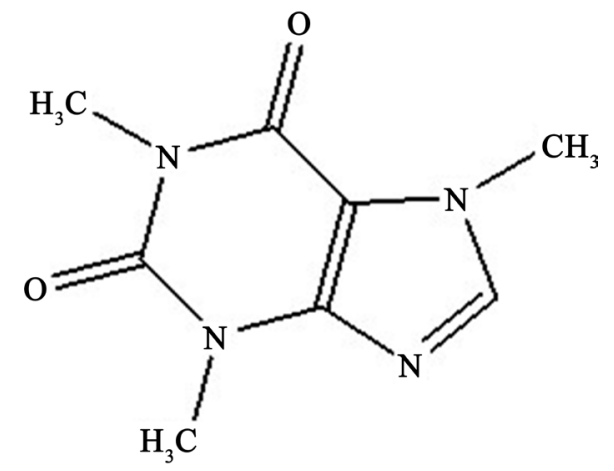

Scheme 1. Chemical structure of caffeine (3,7-dihydro-1,3,7-trimethyl-1H purine-2,6-dione or 1,3,7-trimethylxanthine). 
transfer and to their strong electrocatalytic ability in electrochemical reactions [27]. Thus, their application as new effective electrocatalysts for various chemical and biochemical reactions and in the design of electrochemical sensors is undergoing increasing investigation [28]. Therefore, it is expected that, by combining fullerenes carbon nanotubes and nafion as unique electrode modifier, a synergistic effect of these components could lead to a sensitive sensor.

The present work describes the determination of caffeine via differential pulse voltammetry (DPV) using a glassy carbon electrode (GCE) modified by fullerene/MWCNT and nafion. Prior to its use for electroanalytical studies, the thin film electrode (fullerene/MWCNT/Naf) was characterized by electrochemical impedance spectroscopy (EIS) and cyclic voltammetry (CV). Some parameters were investigated to obtain the best conditions for caffeine determination.

\section{Experimental}

\subsection{Apparatus and Reagents}

Electrochemical measurements were carried out using the Origalys Potentiostat running with the OrigaMaster 5 software. A standard single compartment three-electrode cell was used, with an $\mathrm{Ag} / \mathrm{AgCl}(3 \mathrm{M} \mathrm{KCl})$ reference electrode and a stainless-steel rod counter electrode. The working electrode was a fullerene/MWCNT/Naf modified GCE prepared as described below. All chemicals were commercially supplied: caffeine $\left(\mathrm{C}_{8} \mathrm{H}_{10} \mathrm{~N}_{4} \mathrm{O}_{2}\right)$, dopamine hydrochloride and D-(+)-glucose from Sigma-Aldrich; citric acid monohydrate (J.T. Baber); $\mathrm{K}_{4}\left[\mathrm{Fe}(\mathrm{CN})_{6}\right], \mathrm{K}_{3}\left[\mathrm{Fe}(\mathrm{CN})_{6}\right]$ (Prolabo), $\mathrm{NaOH}$ and $\mathrm{NaCl}$ (Fisher scientific international), $\mathrm{H}_{2} \mathrm{SO}_{4}, \mathrm{CH}_{3} \mathrm{COOH}, \mathrm{HClO}_{4}, \mathrm{HNO}_{3}$ and $\mathrm{HCl}$ (Reidel-de-Haen) were used without further purification. Fullerene/MWCNT powder mixture (95\%, 3 - 20 $\mathrm{nm}$ OD, 2 - $5 \mathrm{~nm}$ ID, 0.1 - $10 \mu \mathrm{m}$ length) and Nafion (5\% w/w in EtOH) were obtained from Alfa Aesar. All solutions were prepared using purified water.

\subsection{GCE Surface Modification}

Prior to its modification by drop-coating, each GCE was polished with alumina pastes on a billiard cloth. They were then placed in a 1:1 ethanol-water solution and properly cleaned in a sonicator for $10 \mathrm{~min}$ to eliminate any remaining alumina particles. $3 \mathrm{mg}$ of fullerene/MWCNT were dispersed in $1 \mathrm{~mL}$ Nafion (1\%) and then in $1 \mathrm{~mL}$ ethanol by ultrasonication to give homogeneous fullerene/ MWCNT/Naf and fullerene/MWCNT dispersions. The GCE surface was coated with $2 \mu \mathrm{L}$ of each resulting dispersion and dried at room temperature for $15 \mathrm{~min}$ to obtain the working electrode (hereafter referred as fullerene/MWCNT/Naf/ GCE). For comparison purposes, a bare GCE covered by a thin film of nafion (Naf/GCE) was also prepared.

\subsection{Electrochemical Procedure}

Cyclic voltammograms were recorded in $\mathrm{HClO}_{4}$ solution containing a given concentration of $\mathrm{CAF}$, in the potential range from $+0.6 \mathrm{~V}$ to $+1.8 \mathrm{~V}$. For trace 
analysis of caffeine, DPV was performed using the following optimized parameters: pulse amplitude $50 \mathrm{mV}$, step potential $5 \mathrm{mV}$, initial potential $+1.0 \mathrm{~V}$, final potential $+1.7 \mathrm{~V}$, equilibrium time $5 \mathrm{~s}$. The GCE before and after its modification was characterized by EIS set at the frequency range from $1 \mathrm{kHz}$ to $0.01 \mathrm{~Hz}$, and with an amplitude of $15 \mathrm{mV}$.

For real sample analysis, two pharmaceutical preparations were purchased locally. The analyzed solutions were obtained by dissolving a capsule of Brupanax and Pipadol (Extra) drugs in $\mathrm{HClO}_{4}$. The corresponding molar concentration of the solutions was calculated and a chosen volume of each of them directly added to the measurement cell. For chronocoulometric measurements, the potential was stepped from $0.0 \mathrm{~V}$ to $+1.4 \mathrm{~V}$ for a period of $1 \mathrm{~min}$ with a sample time of $0.2 \mathrm{~s}$.

\section{Results and Discussion}

\subsection{Electrochemical Behavior of CAF at the Fullerene/MWCNT/Naf/GCE}

Figure 1 shows the cyclic voltammetric responses recorded at $100 \mathrm{mV} \cdot \mathrm{s}^{-1}$ in 0.1 mol. $\mathrm{L}^{-1} \mathrm{HClO}_{4}$ of $10^{-3} \mathrm{~mol} \cdot \mathrm{L}^{-1} \mathrm{CAF}$ at the bare GCE (Figure $1(\mathrm{a})$ ), on Naf/GCE (Figure 1(b)), and on fullerene/MWCNT/Naf/GCE (Figure 1(c)). One can notice that, on fullerene/MWCNT/Naf/GCE the peak current is significantly higher than those registered on the bare GCE and on Naf/GCE. The oxidation process of CAF on all electrodes is irreversible, which is consistent with other reports [29]. The oxidation mechanism of CAF has been revealed by Hansen et al. [30]. Compared with the GCE andie, Naf/GCE, the oxidation potential at the fullerene/MWCNT/Naf/GCE shifted negatively from 1.522 to $1.393 \mathrm{~V}$. This phenomenon may be an evidence of catalytic effect of fullerene/MWCNT, associated to its large specific surface area [31] [32].

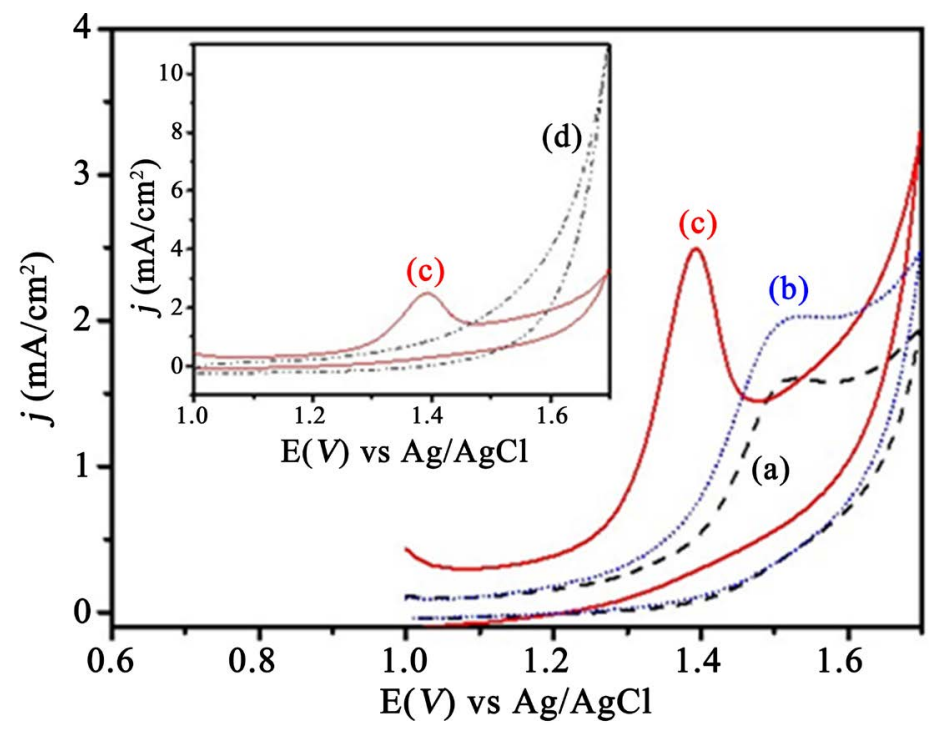

Figure 1. Cyclic voltammograms of $10^{-3} \mathrm{M} \mathrm{CAF}$ recorded in $0.1 \mathrm{M} \mathrm{HClO}_{4}$ at $100 \mathrm{mV} \cdot \mathrm{s}^{-1}$ on (a) bare GCE, (b) Naf/GCE and (c) fullerene/MWCNT/Naf/GCE. (d): blank electrolyte on fullerene/MWCNT/Naf/GCE. 


\subsection{Electrochemical Impedance Spectroscopy (EIS)}

EIS is a valuable method to characterize the electron transfer properties of the electrode surface during the modification process [33]. Figure 2 presents the EIS curves recorded in $1.0 \mathrm{mM}\left[\mathrm{Fe}(\mathrm{CN})_{6}\right]^{3-/ 4-}$ using the bare GCE, Naf/GCE and fullerene/MWCNT/Naf/GCE. The resistance of charge transfer $\left(\mathrm{R}_{\mathrm{ct}}\right)$ deriving from the recorded Nyquist plots with the lowest value $\left(14 \mathrm{k} \Omega \cdot \mathrm{cm}^{2}\right)$ was obtained on the unmodified GCE (inset in Figure 2). Upon the modification of this later using only a nafion film, the $\mathrm{R}_{\mathrm{ct}}$ increased to $18.77 \mathrm{k} \Omega \cdot \mathrm{cm}^{2}$ and further to 64.31 $\mathrm{k} \Omega \cdot \mathrm{cm}^{2}$ on fullerene/MWCNT/Naf/GCE. This is indicative of a better electrode surface coverage with a non-conductive film from the bare GCE to fullerene/ MWCNT/Naf/GCE.

\subsection{Chronocoulometric Study}

The electrochemical effective surface area of the GCE and fullerene/MWCNT/ Naf/GCE was calculated from the slope of the plot of $\mathrm{Q}$ versus $\mathrm{t}^{1 / 2}$ obtained by chronocoulometry (Figure 3) using $1.0 \mathrm{mM} \mathrm{K}_{3}\left[\mathrm{Fe}(\mathrm{CN})_{6}\right]$ as model complex based on Equation (1) [34] where A is the effective surface area of the working electrode, $\mathrm{C}$ is the concentration of the analyte, $\mathrm{n}$ is the number of electrons transferred $\left(\mathrm{n}=1\right.$ for $\left[\mathrm{Fe}(\mathrm{CN})_{6}\right]^{4-/ 3-}$ redox system) and $\mathrm{D}$ is the diffusion coefficient of the analyte $\left(7.6 \times 10^{-6} \mathrm{~cm}^{2} / \mathrm{s}\right.$ for $\left.\left[\mathrm{Fe}(\mathrm{CN})_{6}\right]^{4-/ 3-}\right)$ [35]; $Q_{d l}$ is the capacitive or double layer charge and $Q_{a d s}$ is the faradaic component due to the oxidation of adsorbed species.

$$
Q=\left(2 n F A C D^{\frac{1}{2}} \pi^{\frac{1}{2}}\right) t^{1 / 2}+Q_{d l}+Q_{a d s}
$$

Based on the slope of the linear relationship between $Q$ and $t^{1 / 2}$ (Figure 3(A)),



Figure 2. Nyquist diagrams recorded in $0.1 \mathrm{M} \mathrm{KCl}$ containing $10^{-3} \mathrm{M}\left[\mathrm{Fe}(\mathrm{CN})_{6}\right]^{-3 /-4}$ on (a) bare GCE, (b) Naf/GCE and (c) Fullerene/MWCNT/Naf/GCE. Frequency range: 1 $\mathrm{kHz}-0.01 \mathrm{~Hz}$, amplitude: $15 \mathrm{mV}$. Inset: $R_{c t}$ as a function of electrodes' type. 

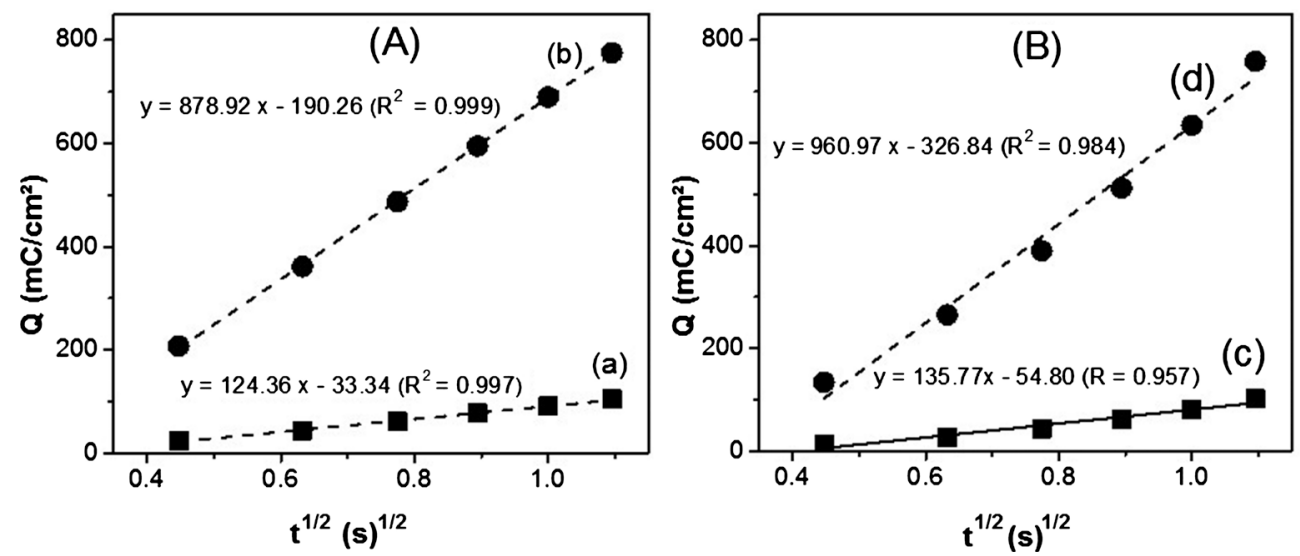

Figure 3. (A) Plot of $\mathrm{Q}$ versus $\mathrm{t}^{1 / 2}$ of $1.0 \mathrm{mM} \mathrm{K}_{3}\left[\mathrm{Fe}(\mathrm{CN})_{6}\right]$ at GCE (curve (a)), fullerene/ MWCNT/Naf/GCE (curve (b)). (B) Plot of $Q$ versus $\mathrm{t}^{1 / 2}$ of $1.0 \mathrm{mM}$ caffeine at GCE (curve (c)) fullerene/MWCNT/Naf/GCE (curve (d)).

the effective surface area A was evaluated to be $0.029 \mathrm{~cm}^{2}$ and $0.206 \mathrm{~cm}^{2}$, for GCE and fullerene/MWCNT/Naf/GCE, respectively. This increase in effective electrode surface upon modification of the GCE with fullerene/MWCNT and Naf accounts for the enhancement of the oxidation peak current of caffeine. This is also a further proof of successful immobilization of the fullerene/MWCNT/ Naf film on the GCE surface.

The diffusion coefficient of $1.0 \mathrm{mM} \mathrm{CAF}$ at GCE and fullerene/MWCNT/ Naf/GCE was calculated from Equation (1), using the values of surface area of GCE and fullerene/MWCNT/Naf/GCE. The value obtained at the developed sensor $\left(1.146 \times 10^{-4} \mathrm{~cm}^{2} \cdot \mathrm{s}^{-1}\right)$ is higher than that obtained at the bare GCE $(9.688$ $\left.\times 10^{-5} \mathrm{~cm}^{2} \cdot \mathrm{s}^{-1}\right)$, thereby confirming the sensitivity of developed sensor toward CAF oxidation (Figure 3(B)).

\subsection{Effect of Scan Rate}

The effect of potential scan rate $(v)$ on the DPV current density $\left(j_{p a}\right)$ and peak potential $\left(\mathrm{E}_{\mathrm{pa}}\right)$ on fullerene/MWCNT/Naf/GCE in $0.1 \mathrm{M} \mathrm{HClO}_{4}(\mathrm{pH} 1)+10^{-3} \mathrm{M}$ $\mathrm{CAF}$ was investigated by CV (Figure 4). As observed, $\mathrm{E}_{\mathrm{pa}}$ shifted to a positive value with an increase of the scan rate, along with a concurrent increase in anodic peak current. A plot of $\log j_{p a} v s \log v$ (result not shown) was used to determine whether the oxidative behavior of CAF was due to diffusion or adsorption. The slope of $0.87>0.5$ for a theoretical diffusion-controlled process allowed to conclude that a mixed behavior showing both adsorption and diffusion-controlled processes were involved [36]. When the scan rate increased, the anodic peak potential at the fullerene/MWCNT/Naf/GCE shifted positively. For further verification of the value of $\alpha$, the Laviron equation for an irreversible electrode process was used [37]:

$$
E_{p a}=E^{0}+\frac{R T}{\alpha n F} \ln \frac{R T K^{0}}{\alpha n F}+\frac{R T}{\alpha n F} \ln v
$$

where $E^{0}$ is formal potential, $k^{0}$ is heterogeneous electron transfer rate constant, 



Figure 4. Cyclic voltammograms of $10^{-3} \mathrm{M} \mathrm{CAF}$ at fullerene/MWCNT/Naf/GCE in $0.1 \mathrm{H}_{2} \mathrm{SO}_{4}$ at different scan rates $\left(10,20,30,45,70,80\right.$ and $\left.100 \mathrm{mV} \cdot \mathrm{s}^{1}\right)$. Inset (A) $j_{p a}$ as a function of $\mathrm{v}^{1 / 2}$ and (B) $\mathrm{E}_{\mathrm{pa}}$ as a function of $\ln v$.

$\alpha$ is electron transfer coefficient, $n$ is the number electron transferred in the rate determining step and $v$ is the scan rate. $R=8.314 \mathrm{~J} \cdot \mathrm{mol}^{-1} \cdot \mathrm{K}^{-1}, T=298 \mathrm{~K}$ and $F=$ $96.480 \mathrm{C} \cdot \mathrm{mol}^{-1}$ have their usual meanings. In this work, $E_{p a}=1.272+0.0301 \ln V$ $\left(E_{p a}\right.$ in $\mathrm{V}, v$ in $\mathrm{mV} \cdot \mathrm{s}^{-1}, \mathrm{R}=0.998$ ), the electron transfer number $(n)$ was 4 [38], and the electron transfer coefficient $(\alpha)$ was estimated to be 0.426 .

\subsection{Effect of Supporting Electrolyte and Its pH}

Usually, the nature of the electrolyte solution affects the electrochemical behavior of the analyte, as it was observed in previous studies for CAF [38] [39] [40] [41]. The electrooxidation of CAF involving protons, different decimolar acidic solutions $\left(\mathrm{H}_{2} \mathrm{SO}_{4}, \mathrm{HClO}_{4}, \mathrm{CH}_{3} \mathrm{COOH}\right.$, and $\left.\mathrm{HCl}\right)$ were tested for the differential pulse voltammetric determination of CAF on fullerene/MWCNT/Naf/GCE.

Although a peak was recorded for all investigated solutions, $\mathrm{HClO}_{4}$ generated the best signal in terms of shape and intensity. This allowed to use $0.1 \mathrm{M} \mathrm{HClO}_{4}$ as supporting electrolyte for further experiments. The redox behavior of most biomolecules is affected by the $\mathrm{pH}$ of supporting electrolyte [42]. In this study, the effect of $\mathrm{pH}$ on peak current $\left(j_{p a}\right)$ and peak potential $\left(\mathrm{E}_{\mathrm{pa}}\right)$ of CAF was evaluated within the acidic $\mathrm{pH}$ range $(0.5-2.5)$. From $\mathrm{pH} 0.5$, the peak current increased slightly at $\mathrm{pH} 1$, then decreased from $\mathrm{pH} 1.0$ to $\mathrm{pH} 2.5$ (Figure 5(A)). one can also observe that the anodic peak potential of CAF shifted towards less positive values as the $\mathrm{pH}$ changes from 0.5 to 2.5 (Figure $5(\mathrm{~B})$ ). Therefore, $\mathrm{pH}$ 1.0 was chosen for the subsequent experiments (Figure 5 ).

\subsection{Interference Study, Repeatability and Stability of the Electrode}

The next step in the work focused on the evaluation of the specificity of the sensor when operating in the presence of interfering agents frequently found in commercialized drinks and drugs. A CAF solution $\left(10^{-4} \mathrm{~mol} \cdot \mathrm{L}^{-1}\right)$ spiked with various species was evaluated under the same experimental conditions in $0.1 \mathrm{M}$ $\mathrm{HClO}_{4}$ by DPV. The selected interfering compounds include citric acid, sulfite 
ions, glucose and dopamine that were added in the electrochemical cell, with concentrations 100 to 200 -fold higher than that of CAF $\left(10^{-4} \mathrm{~mol} \cdot \mathrm{L}^{-1}\right)$. The tolerance limit, defined as the concentration ratio of the additive over CAF causing $\pm 5.0 \%$ relative error was used to measure the interfering effect. The results obtained (Table 1) showed that the oxidation peak of CAF is slightly affected by citric acid as more than 100-fold excess of this compound did not significantly influence the peak current of caffeine. However, dopamine and sulfite ions were the most interfering agents, somewhat limiting the selectivity of the proposed sensor for media containing high amount of such interfering compounds.

Several measurements were performed to determine the repeatability of the electrochemical responses of fullerene/MWCNT/Naf modified GCE for $1.0 \mathrm{mM}$ $\mathrm{CAF}$ in $0.1 \mathrm{M} \mathrm{HClO}_{4}$ solution. The results of ten successive measurements showed a relative standard deviation of $4.56 \%$ for CAF, indicating that the proposed modified GCE has good repeatability. The long-term stability of the electrode was also evaluated by measuring the response for $1.0 \mathrm{mM}$ CAF after keeping the electrode in $\mathrm{HClO}_{4}$ solution for 7 days. The electrode retained about 95\% of its original activity for CAF, indicating the electrode was very stable.
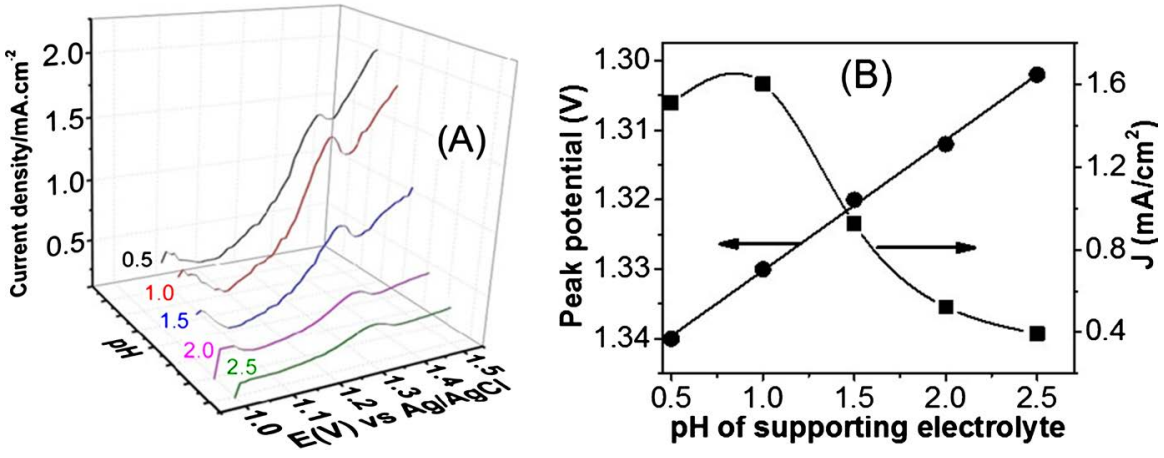

Figure 5. (A) Effect of detection medium $\mathrm{pH}(0.5,1,1.5,2$, and 2.5) on the anodic peak position of $10^{-4} \mathrm{M} \mathrm{CAF}$, at fullerene/MWCNT/Naf/GCE. (B) Variation of the peak current as a function of $\mathrm{pH}$ of the detection medium $\left(\mathrm{HClO}_{4}\right)$ and peak potential as a function of the $\mathrm{pH}$ of the detection medium.

Table 1. Interference study on the determination of $10^{-4} \mathrm{M}$ CAF.

\begin{tabular}{ccc}
\hline \multirow{2}{*}{ Species } & $\begin{array}{c}\text { Concentration } \\
(1 \mu \mathrm{M})\end{array}$ & \% variation in the DPV peak current (with CAF $=100 \%)$ \\
\cline { 3 - 3 } Citric acid & 100 & Fullerene/MWCNT/Naf/GCE \\
& 200 & 5.31 \\
Sulfite & 100 & -11.99 \\
& 200 & -18.74 \\
Glucose & 100 & -5.76 \\
& 200 & -14.41 \\
Dopamine & 100 & -19.43 \\
& 200 & -20.06 \\
\hline
\end{tabular}




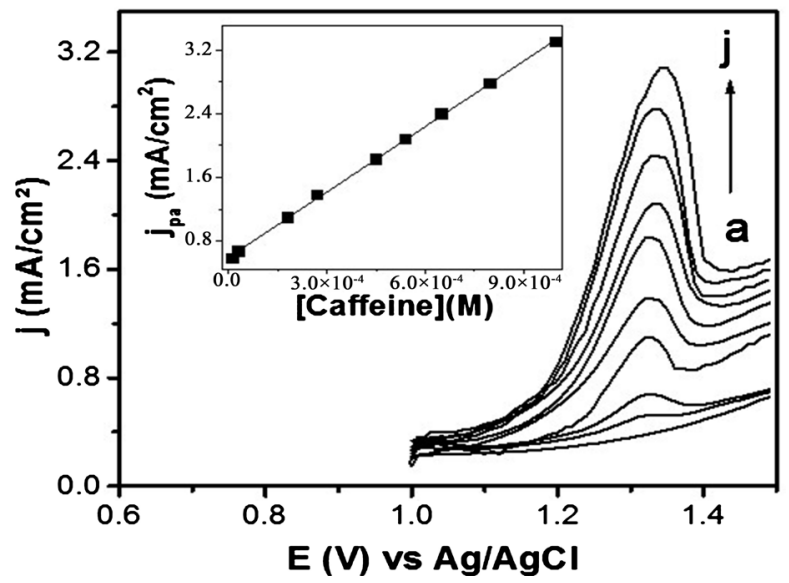

Figure 6. DPV curves obtained under optimized conditions in $0.1 \mathrm{M} \mathrm{HClO}_{4}(\mathrm{pH} 1)$ at fullerene/MWCNT/Naf/GCE for various concentrations of CAF (a - j): 0, 10, 30, 180, 270, $450,540,650,800$ and $1000 \mu \mathrm{M}$. The inset shows the corresponding calibration graph.

Table 2. Comparison of the performance of some CAF sensors.

\begin{tabular}{cccc}
\hline Electrode type configuration & $\begin{array}{c}\text { Solution } \\
\mathrm{pH}\end{array}$ & $\begin{array}{c}\text { LOD } \\
(\mu \mathrm{M})\end{array}$ & Ref. \\
\hline Graphene oxide-Nafion/GCE & 2.0 & 0.20 & {$[22]$} \\
MWCNT-Nafion/GCE & 4.1 & 0.51 & {$[43]$} \\
Nafion/GCE & 1.0 & 0.79 & {$[23]$} \\
Nafion/MWCNT/GCE & 2.0 & 0.23 & {$[21]$} \\
Attapulgite/Nafion/GCE & 1.5 & 0.045 & {$[26]$} \\
4-Cu'ITAPc/SAM/GCE & 4.0 & 0.0304 & {$[44]$} \\
ZnO/MWCNT/GCE & 1.0 & 0.0097 & {$[45]$} \\
Pt-GR/GCE & $/$ & 0.1129 & {$[46]$} \\
GORG/CPE/SDS & 1.0 & 0.153 & {$[47]$} \\
GrRAC-70\% & $/$ & 2.94 & {$[48]$} \\
NCOM/CPE/SDS & 0.75 & 0.016 & {$[49]$} \\
3D-printed cell-on-a-chip & $/$ & 2.84 & {$[50]$} \\
GCE & $/$ & 20 & {$[51]$} \\
Nafion/PDDA-MWCNT/GCE & 1.5 & 0.05 & {$[52]$} \\
Fullerene/MWCNT/Naf/GCE & 1.0 & 0.072 & This work \\
\hline
\end{tabular}

LOD: Low limit of detection, 4-CuIITAPc: Copper (II) phthalocyanine. SAM: Self-assembled monolayer, Pt-GR: Platinum graphene, GORG: Graphene oxide-reduced glutathione, SDS: Sodium dodecylsulfate, NCOM: Nano-Cobalt (II, III) oxide modified, GrRAC: Cork-graphite, PDDA: Poly (diallyldimethylammonium chloride).

Table 3. Determinations of CAF in pharmaceutical tablets using standard addition method $[26]$.

\begin{tabular}{cccc}
\hline Sample & Labeled amounts $(\mathbf{m g})$ & Detected amount $(\mathrm{mg})$ & Recovery (\%) \\
\hline Brupanax & 30 & $29.31 \pm 0.73$ & 97.71 \\
Pipadol Extra & 30 & $28.70 \pm 0.78$ & 95.66 \\
\hline
\end{tabular}




\subsection{Variation of CAF Concentration, Calibration Graph and Analytical Application}

The DPV curves of CAF in the concentration range from 10 to $1000 \mu \mathrm{M}$ at fullerene/MWCNT/Naf/GCE in $0.1 \mathrm{M} \mathrm{HClO}_{4}$ (pH 1.0) are shown in Figure 6.

The recorded peak current increased linearly with an increase in the concentration of CAF. A calibration plot of the oxidation peak current against CAF concentration is linear, with a correlation coefficient of 0.999 and a detection limit of $72.89 \mathrm{nM}(\mathrm{S} / \mathrm{N}=3)$.

As compared with other modified electrodes, it is obvious that the present method is comparable or better in the determination of CAF since it provides a significantly low detection limit (Table 2). On the other hand, the preparation of the modified electrode is simple and reproducible.

The applicability of the developed method to the determination of caffeine in real samples was investigated using the standard addition method. The experimentally detected values and the labeled values are compared in Table 3. It was found that the results obtained using fullerene/MWCNT/Naf/GCE are in a good agreement with the content label.

\section{Conclusion}

This work showed the ability of fullerene/MWCNT/Naf/GCE electrode towards the electrochemical quantification of caffeine. The obtained results showed that the electrocatalytic oxidation of caffeine at the surface of the modified electrode occurs at a potential of about $1.33 \mathrm{~V}$. The anodic peak current of caffeine was proportional to the concentration in the range from 10 to $1000 \mu \mathrm{M}$, with a detection limit $72.89 \mathrm{nM}$ and correlation coefficient of 0.999 . The simple preparation, good stability, excellent reproducibility, sensitivity and rapid analysis make the developed method suitable for routine determination of caffeine in real samples.

\section{Acknowledgements}

The authors acknowledge the support of The World Academy of Sciences (TWAS) for the advancement of science in developing countries (RGA N ${ }^{\circ} 16-515$ RG/ CHE/AF/AC_G-FR3240293302) allowed to Ignas K. Tonle.

\section{Conflicts of Interest}

The authors declare no conflicts of interest regarding the publication of this paper.

\section{References}

[1] Osman, H., Nasarudin, R. and Lee, S.L. (2004) Extracts of cocoa (Theobroma cacao L.) Leaves and Their Antioxidation Potential. Food Chemistry, 86, 41-46. https://doi.org/10.1016/j.foodchem.2003.08.026

[2] Fernandes, D.M., Silva, N., Pereira, C., Moura, C., Magalhães, J.M.C.S., Bachiller-Baeza, B., Rodríguez-Ramos, I., Guerrero-Ruiz, A., Delerue-Matos, C. and 
Freire, C. (2015) $\mathrm{MnFe}_{2} \mathrm{O}_{4} @ \mathrm{CNT}-\mathrm{N}$ as Novel Electrochemical Nanosensor for Determination of Caffeine, Acetaminophen and Ascorbic Acid. Sensors and Actuators B: Chemical, 218, 128-136. https://doi.org/10.1016/j.snb.2015.05.003

[3] Ferruzzi, M.G. (2010) The Influence of Beverage Composition on Delivery of Phenolic Compounds from Coffee and Tea. Physiology \& Behavior, 100, 33-41. https://doi.org/10.1016/j.physbeh.2010.01.035

[4] Furtado, L. de A., Gonçalves, M.C. de O., Inocêncio, C.V.M., Pinto, E.M., Martins, D. de L. and Semaan, F.S. (2019) Electrodeposition of 4-Benzenesulfonic Acid onto a Graphite-Epoxy Composite Electrode for the Enhanced Voltammetric Determination of Caffeine in Beverages. Journal of Analytical Methods in Chemistry, 2019, Article ID: 8596484. https://doi.org/10.1155/2019/8596484

[5] Cauli and Morelli, M. (2005) Caffeine and the Dopaminergic System. Behavioural Pharmacology, 16, 63-77. https://doi.org/10.1097/00008877-200503000-00001

[6] Yemane, T., Rishi, P., Abraha, T., Amaha, W. and Ram, C.S. (2015) Voltammetric Reckoning of Caffeine at Trace Level in Local Available Drinks and Pharmaceutical Formulations. International Journal of Scientific and Research Publications, 5, 1-7.

[7] Rostagno, M.A., Manchon, N., D’Arrigo, M., Guillamon, E., Villares, A., Garcia-Lafuente, A., Ramos, A. and Martinez, J.A. (2011) Fast and Simultaneous Determination of Phenolic Compounds and Caffeine in Teas, Mate, Instant Coffee, Soft Drink and Energetic Drink by High-Performance Liquid. Analytica Chimica Acta, 685, 204-211. https://doi.org/10.1016/j.aca.2010.11.031

[8] Chen, Q., Guo, Z. and Zhao, J. (2008) Identification of Green Tea's (Camellia sinensis (L.)) Quality Level According to Measurement of main Catechins and Caffeine Contents by HPLC and Support Vector. Journal of Pharmaceutical and Biomedical Analysis, 48, 1321-1325. https://doi.org/10.1016/j.jpba.2008.09.016

[9] Khoo, W.Y.H., Pumera, M. and Bonanni, A. (2013) Graphene Platforms for the Detection of Caffeine in Real Samples. Analytica Chimica Acta, 804, 92-97. https://doi.org/10.1016/j.aca.2013.09.062

[10] Svítková, J., Machková, M., Šatkovská, P., Cinková, K. and Švorc L (2012) Utilization of Electrochemical Methods in Determination of Trace Elements in Beverages. Acta Chimica Slovaca, 5, 42-46. https://doi.org/10.2478/v10188-012-0007-1

[11] Smith, A., Sutherland, D. and Christopher, G. (2005) Effects of Repeated Doses of Caffeine on Mood and Performance of Alert and Fatigued Volunteers. Journal of Psychopharmacology, 19, 620-626. https://doi.org/10.1177/0269881105056534

[12] Arinobu, T., Hattori, H., Kumazawa, T., Lee, X.P., Mizutani, Y., Katase, T., Kojima, S., Omori, T., Kaneko, R., Ishii, A. and Seno, H. (2009) High-Throughput Determination of Theophylline and Caffeine in Human Serum by Conventional Liquid Chromatography-Mass Spectrometry. Forensic Toxicology, 27, 1-6.

https://doi.org/10.1007/s11419-008-0058-6

[13] Evans, R.L. and Siitonen, P.H. (2008) Determination of Caffeine and Sympathomimetic Alkaloids in Weight Loss Supplements by High-performance Liquid Chromatography. Journal of Chromatographic Science, 46, 61-67.

https://doi.org/10.1093/chromsci/46.1.61

[14] Jafari, M.T., Rezaei, B. and Javaheri, M. (2011) A New Method Based on Electrospray Ionisation Ion Mobility Spectrometry (ESI-IMS) for Simultaneous Determination of Caffeine and Theophylline. Food Chemistry, 126, 1964-1970. https://doi.org/10.1016/j.foodchem.2010.12.054

[15] Tzanavaras, P.D. and Themelis, D.G. (2007) Development and Validation of a High-Throughput High-Performance Liquid Chromatographic Assay for the De- 
termination of Caffeine in Food Samples Using a Monolithic. Analytica Chimica Acta, 581, 89-94. https://doi.org/10.1016/j.aca.2006.07.081

[16] Aranda, M. and Morlock, G. (2007) Simultaneous Determination of Caffeine, Ergotamine, and Metamizol in Solid Pharmaceutical Formulation by HPTLC-UV-FLD with Mass Confirmation by online HPTLC. Journal of Chromatographic Science, 45, 251-255. https://doi.org/10.1093/chromsci/45.5.251

[17] Rocha, R.G., Stefano, J.S., Arantes, I.V.S., Ribeiro, M.M.A.C., Santana, M.H.P., Richter E.M. and Munoz, R.A.A. (2019) Simple Strategy for Selective Determination of Levamisole in Seized Cocaine and Pharmaceutical Samples Using Disposable Screen-Printed Electrodes. Electroanalysis, 31, 153-159. https://doi.org/10.1002/elan.201800716

[18] Sontag, G. and Kral, K. (1979) Voltammetric Determination of Caffeine in Coffee, Tea and Soft Drinks. Mikrochimica Acta, 71, 229-240. https://doi.org/10.1007/BF01196409

[19] Suw, Y.L., Young, S.J.H., Myung, K., In, K.H., Woon, W.J. and Hyun, S.K. (2004) Determination of Caffeine Using a Simple Graphite Pencil Electrode with Square-Wave Anodic Stripping Voltammetry. Microchimica Acta, 146, 207-213. https://doi.org/10.1007/s00604-004-0209-3

[20] Sundari, P.L.A., Palaniappan, S.P. and Manisankar, P. (2010) Enhanced Sensing of Carbendazim, a Fungicide on Functionalized Multiwalled Carbon Nanotube Modified Glassy Carbon Electrode and its Determination in Real Samples. Analytical Letters, 43, 1457-1470. https://doi.org/10.1080/00032710903502066

[21] Martínez-Huitle, C.A., Fernandes, N.S., Ferro, S., Battisti, A. and Quiroz, M.A. (2010) Fabrication and Application of Nafion-Modified Boron-Doped Diamond Electrode as Sensor for Detecting Caffeine. Diamond Related Materials, 19, 1188-1193. https://doi.org/10.1016/j.diamond.2010.05.004

[22] Yang, S., Yang, R., Li, G., Qu, L., Li, J. and Yu, L. (2010) Nafion/Multi-Wall Carbon Nanotubes Composite Film Coated Glassy Carbon Electrode for Sensitive Determination of Caffeine. Journal of Electroanalytical Chemistry, 639, 77-82. https://doi.org/10.1016/j.jelechem.2009.11.025

[23] Zhao, F., Wang, F., Zhao, W., Zhou, J., Liu, Y. and Zou, I. (2011) Voltammetric Sensor for Caffeine Based on a Glassy Carbon Electrode Modified with Nafion and Graphene Oxide. Microchimica Acta, 174, 383-390.

https://doi.org/10.1007/s00604-011-0635-y

[24] Carolina, A.T., Madalina, M.B. and Christopher, M.A.B. (2014) Simple Electrochemical Sensor for Caffeine Based on Carbon and Nafion-Modified Carbon Electrodes. Food Chemistry, 149, 215-220. https://doi.org/10.1016/j.foodchem.2013.10.114

[25] Hernandez-Aldave, S., Tarat, A., McGettrick, J.D. and Bertoncello, P. (2019) Voltammetric Detection of Caffeine in Beverages at Nafion/Graphite Nanoplatelets Layer-by-Layer Films. Nanomaterials, 9, E221. https://doi.org/10.3390/nano9020221

[26] Tajeu, K.Y., Ymele, E., Jiokeng, S.L.Z. and Tonle, I.K. (2018) Electrochemical Sensor for Caffeine Based on a Glassy Carbon Electrode Modified with an Attapulgite/Nafion Film. Electroanalysis, 31, 350-356. https://doi.org/10.1002/elan.201800621

[27] Zen, J.M., Ting, Y.S. and Shih, Y. (1998) Voltammetric Determination of Caffeine in Beverages Using a Chemically Modified Electrode. Analyst, 123, 1145-1147. https://doi.org/10.1039/a708360b

[28] Sherigara, B.S., Kutner, W. and De Souza, F. (2003) Electrocatalytic Properties and 
Sensor Applications of Fullerenes and Carbon Nanotubes. Electroanalysis, 15, 753-772. https://doi.org/10.1002/elan.200390094

[29] Xie, X., Gan, T., Sun, D. and Wu, K. (2008) Application of Multi-Walled Carbon Nanotubes/Nafion Composite Film in Electrochemical Determination of $\mathrm{Pb}^{2+}$. Fullerenes, Nanotubes and Carbon Nanostructures, 16, 103-113. https://doi.org/10.1080/15363830801887935

[30] Torres, A.C., Barsan, M.M. and Brett, C.M.M. (2014) Simple Electrochemical Sensor for Caffeine Based on Carbon and Nafion-Modified Carbon Electrodes. Food Chemistry, 149, 215-220. https://doi.org/10.1016/j.foodchem.2013.10.114

[31] Hansen, B.H. and Dryhurst, G. (1971) Electrochemical Oxidation of Theobromine and Caffeine at the Pyrolytic Graphite Electrode. Journal of Electroanalytical Chemistry and Interfacial Electrochemistry, 30, 407-416.

https://doi.org/10.1016/0368-1874(71)87024-7

[32] Tsai, Y.C., Chen, J.M., Li, S.C. and Marken, F. (2004) Electroanalytical Thin Film Electrodes Based on a Nafion Multi-Walled Carbon Nanotube Composite. Electrochemistry Communications, 6, 917-922. https://doi.org/10.1016/j.elecom.2004.07.003

[33] Guo, R.X., Xu, Q., Wang, D.Y. and Hu, X.Y. (2008) Trace Determination of Clenbuterol with an MWCNT-Nafion Nanocomposite Modified Electrode. Microchimica Acta, 161, 265-272. https://doi.org/10.1007/s00604-007-0766-3

[34] Inzelt, G. (2010) Chronocoulometry. In: Scholz, E., et al., Eds., Electroanalytical Methods: Guide to Experiments and Applications, 2nd Edition, Springer Verlag, Berlin, 147-158. https://doi.org/10.1007/978-3-642-02915-8_7

[35] Yin, H., Zhou, Y., Xu, J., Ai, S., Cui, L. and Zhu, L. (2010) Amperometric Biosensor Based on Tyrosinase Immobilized onto Multiwalled Carbon Nanotubes-Cobalt Phthalocyanine-Silk Fibroin Film and Its Application to Determine. Analytica Chimica Acta, 659, 144-150. https://doi.org/10.1016/j.aca.2009.11.051

[36] Qu, L.N., Wu, J., Sun, X.Y., Xi, M.Y. and Sun, W. (2010) Application of Multi-Walled Carbon Nanotube Modified Carbon Ionic Liquid Electrode for the Voltammetric Detection of Dopamine. Journal of the Chinese Chemical Society, 57, 701-707. https://doi.org/10.1002/jccs.201000098

[37] Chitravathi, S. and Munichandraiah, N. (2016) Voltammetric Determination of Paracetamol, Tramadol and Caffeine Using Poly (Nile Blue) Modified Glassy Carbon Electrode. Journal of Electroanalytical Chemistry, 764, 93-103. https://doi.org/10.1016/j.jelechem.2016.01.021

[38] Spataru, N., Sarada, B.V., Tryk, D.A. and Fujishima, A. (2002) Anodic Voltammetry of Xanthine, Theophylline, Theobromine and Caffeine at Conductive Diamond Electrodes and Its Analytical Application. Electroanalysis, 14, 721-728. https://doi.org/10.1002/1521-4109(200206)14:11<721::AID-ELAN721>3.0.CO;2-1

[39] Sun, J.Y., Huang, K.J., Wei, S.Y., Wu, Z.W. and Ren, F.P. (2011) A Graphene-Based Electrochemical Sensor for Sensitive Determination of Caffeine. Colloids Surfaces B: Biointerfaces, 84, 421-426. https://doi.org/10.1016/j.colsurfb.2011.01.036

[40] Brunetti, B., Desimoni, E. and Casati, P. (2007) Determination of Caffeine at a Nafion-covered Glassy Carbon Electrode. Electroanalysis, 19, 385-388. https://doi.org/10.1002/elan.200603679

[41] Valassi, L., Tsimpliaras, D., Katseli, V., Economou, A., ŠVancara, I., Stočes, M., Mikysek, T. and Prodromidis, M. (2015) Disposable Nafion-Modified Screen-Printed Graphite Electrodes for the Rapid Voltammetric Assay of Caffeine. Insights in Analytical Electrochemistry, 1, 4. https://doi.org/10.21767/2470-9867.100004 
[42] Goyal, R.N., Bishnoi, S. and Agrawal, B. (2011) Electrochemical Sensor for the Simultaneous Determination of Caffeine and Aspirin in Human Urine Samples. Journal of Electroanalytical Chemistry, 655, 97-102. https://doi.org/10.1016/j.jelechem.2011.03.008

[43] Zhang, J., Wang, L.P., Guo, W., Peng, X.D., Li, M. and Yuan, Z.B. (2011) Sensitive Differential Pulse Stripping Voltammetry of Caffeine in Medicines and Cola Using a Sensor Based on Multi-Walled Carbon Nanotubes and Nafion. International Journal of electrochemical science, 6, 997-1006.

[44] Jeevagan, J.A. and John, A.S. (2012) Electrochemical Ddetermination of Caffeine in the Presence of Paracetamol Using a Self-Assembled Monolayer of Non-Peripheral Amine Substituted Copper(II) Phthalocyanine. Electrochimica Acta, 77, 137-142. https://doi.org/10.1016/j.electacta.2012.05.090

[45] Takunda, M., Mambo, M., Jonathan, O.O., Munyaradzi, S., Tichaona, N. and Upenyu, G. (2017) Electrodeposition of Zinc Oxide Nanoparticles on Multiwalled Carbon Nanotube-Modified Electrode for Determination of Caffeine in Wastewater Effluent. International Journal of Environmental Analytical Chemistry, 97, 623-636. https://doi.org/10.1080/03067319.2017.1337898

[46] Qiao, J., Zhang, L.T., Gao, S. and Li, N.B. (2019) Facile Fabrication of Graphene-Supported Pt Electrochemical Sensor for Determination of Caffeine. Applied Biochemistry and Biotechnology, 190, 529-539. https://doi.org/10.1007/s12010-019-03104-Z

[47] Shehataa, M., Azab, S.M. and Fekrya, A.M. (2019) May Glutathione and Graphene Oxide Enhance the Electrochemical Detection of Caffeine on Carbon Paste Sensor in Aqueous and Surfactant Media for Beverages Analysis. Synthetic Metals, 256, Article ID: 116122. https://doi.org/10.1016/j.synthmet.2019.116122

[48] Monteiro, M.K.S., Paiva, S.S.M., da Silva, D.R., Vilar, V.J.P., Martínez-Huitle, C.A. and dos Santos, E.V. (2019) Novel Cork-Graphite Electrochemical Sensor for Voltammetric Determination of Caffeine. Journal of Electroanalytical Chemistry, 839, 283-289. https://doi.org/10.1016/j.jelechem.2019.03.030

[49] Fekry, A.M., Shehata, M., Azab, S.M. and Walcarius, A. (2019) Voltammetric Detection of Caffeine in Pharmacological and Beverages Samples Based on Simple Nano-Co (II, III) Oxide Modified Carbon Paste Electrode in Aqueous and Micellar Media. Sensors and Actuators. B. Chemical, 302, Article ID: 1271722.

https://doi.org/10.1016/j.snb.2019.127172

[50] Katseli, V., Economou, A., and Kokkinos, C., (2019) A Novel All-3D-Printed Cell-on-a-Chip Device as a Useful Electroanalytical Tool: Application to the Simultaneous Voltammetric Determination of Caffeine and Paracetamol. Talanta, 208, Article ID: 120388. https://doi.org/10.1016/j.talanta.2019.120388

[51] Redivo, L., Stredanský, M., Angelis, D.E., Navarini, L., Resmini, M. and Švorc, Ĺ. (2018) Bare Carbon Electrodes as Simple and Efficient Sensors for the Quantification of Caffeine in Commercial Beverages. Royal Society Open Science, 5, Article ID: 172146. https://doi.org/10.1098/rsos.172146

[52] Zhang, Y., Shang, J., Jiang, B., Zhou, X. and Wang, J. (2017) Electrochemical Determination of Caffeine in Oolong Tea Based on Polyelectrolyte Functionalized Multi-Walled Carbon Nanotube. International Journal of Electrochemical Science, 12, 2552-2562. https://doi.org/10.20964/2017.03.02 